\title{
Investigation on Gaseous and Particle Mass Emissions from Automatically Fired Small Scale Heating System Under Laboratory Conditions
}

\author{
Md. Obaidullaha,b, , Svend Bram ${ }^{\mathrm{b}}$ and Jacques De Ruyck ${ }^{\mathrm{b}}$ \\ ${ }^{a}$ Centre for Energy Studies, Bangladesh University of Engineering and Technology, Dhaka, Bangladesh \\ ${ }^{b}$ Department of Mechanical Engineering, Vrije Universiteit Brussel, 1050 Brussels, Belgium
}

\begin{abstract}
This study presents the experimental results on gaseous and particle mass emissions obtained from a bottom feed pellet stove of $2.5 \mathrm{~kW}$ output in part load heat and $5 \mathrm{~kW}$ output in nominal heat. The experiments were conducted in a stove manufacturing plant in the southern part of Belgium. Two combustion experiments (A and B) in part load heat output and four experiments (C, D, E and E) in nominal load were performed at three combustion phases: startup, combustion and burnout phase. The pellet stove was operated in different fan speeds varied from $900 \mathrm{rpm}$ to $1250 \mathrm{rpm}$ for the combustion experiments. Experiments A and B were operated with low speed fan, $\mathrm{C}$ and $\mathrm{D}$ with medium speed fan, $\mathrm{E}$ and $\mathrm{F}$ with high speed fan. The emissions results include $\mathrm{CO}_{2}, \mathrm{CO}, \mathrm{O}_{2}$ and particle mass concentrations are presented in this study. A performance analysis in terms of combustion efficiency together with different losses of the pellet stove is also discussed. The experimental results show that $\mathrm{CO}$ emissions obtained from the main combustion phase of the part load heat output experiments varied from $1215 \mathrm{mg} / \mathrm{Nm}^{3}$ to $1450 \mathrm{mg} / \mathrm{Nm}^{3}$, while in the nominal load heat output varied from 50 $\mathrm{mg} / \mathrm{Nm}^{3}$ to $145 \mathrm{mg} / \mathrm{Nm}^{3}$. Also, the results show that CO emissions in the burnout phase from all the experiments were significantly higher than that in the startup phase followed by the combustion phase. The finding shows that higher CO emissions in the startup and burnout phase have influence on the total CO emissions. Particle mass emissions obtained from the combustion experiments operated with high fan speed varied from $10-15 \mathrm{mg} / \mathrm{Nm}^{3}$ respectively and were much lower than the required limit value of standard EN14785 and other works. The combustion efficiency obtained from all the experiments for the low speed fan, medium speed fan and high speed fan was $92.8 \pm 1.2 \%, 92.4 \pm 1.1 \%$ and $92.7 \pm 1.2 \%$ respectively and satisfied the required limit value of the standard.
\end{abstract}

Keywords: Pellet stove, combustion cycle, gaseous emissions, particle mass emissions, performance analysis

Article History: Received Sept 12 ${ }^{\text {th }}$ 2017; Received in revised form March 17 th 2018; Accepted April 26 ${ }^{\text {th }} 2018$; Available online

How to Cite This Article: Obaidullah, M., Bram, S. and De Ruyck, J. (2018) Investigation on Gaseous and Particle Mass Emissions from Automatically Fired Small Scale Heating System under Laboratory Conditions. Int. Journal of Renewable Energi Development, 7(2), 111-121. https://doi.org/10.14710/ijred.7.2.111-121

\section{Introduction}

The conversion of chemical energy from biomass fuels into thermal energy, involves emissions in form of gaseous and particulate matter which can seriously affect human health and the environment (Chafe et al., 2015; Englert, 2004; Khan et al., 2009; Obaidullah et al., 2014; Obaidullah et al., 2012; Schmidl et al., 2011; Toscano et al.; Vicente et al.). Using wood pellets as biomass fuel is gradually increasing due to their high energy density, easy transportability and the lower amount of gas emissions from its production and transportation comparing to oil, coal and natural gas. Nowadays, combustion of wood pellets in small scale heating appliances is efficient and produces significantly lower emissions than the old wood log combustion appliances. For example, Johansson et al. (Johansson et al., 2004) reported higher gaseous and particle emissions observed for an old boiler compared to a modern appliance using wood pellets. Several studies have been conducted to investigate the emissions and performance of small scale heating appliances at nominal load operations (Ohman et al., 2004; Sippula et al., 2007; Tissari, 2008; Tissari et al., 2009; Vicente and Alves, 2018).

Most of the heating appliances in the market claim an optimized combustion with low emissions of gaseous pollutants at nominal operational load. However, in countries like Belgium, operation at full load is only required for a short peak winter period from November to February (Obaidullah, 2014). For the rest of the year, the combustion appliances may work at lower operational loads as far as continuous operation is considered. The emissions of these pollutants are significantly different if the heating appliance is operating at lower loads i.e. part load. Carbon monoxide (CO) emissions from residential pellet heating devices mainly report during stationary operation, however, a considerable part of un-burnt fuels

* Corresponding author: mdobaidullah@ces.buet.ac.bd 
are emitted during the startup and burnout phases (Fiedler and Persson, 2009; Obaidullah, 2014).

The aim of this study was to investigate gaseous emissions, particle mass concentrations and performance analysis from a bottom feed pellet stove operated with nominal load $(5 \mathrm{~kW})$ and part load $(2.5 \mathrm{~kW})$ output. This study focuses on the emissions from three combustion phases being the startup, combustion (stationary operation) and burnout. The gaseous emissions of $\mathrm{CO}_{2}$ and $\mathrm{O}_{2}$ concentrations were measured continuously by a Horiba PG 250 gas analyzer and CO concentrations were measured continuously by a Siemens Ultramat 6 gas analyzer and the particle mass emissions was measured by a WÖHLER-Staubmessgerät SM 96 instrument using the DINplus device sampling technique. A performance analysis in terms of combustion efficiency together with different losses is also performed. The combustion experiments were conducted in a laboratory of stove manufacturing plant in the southern part of Belgium.

\section{Materials and Methods}

This section briefly discusses the experimental setup, fuel characteristics, combustion appliance and instruments used in the emission measurements. Equations used for the calculation of combustion efficiency and error analysis are also discussed.

\subsection{Experimental setup}

The measurements were conducted according to the European standard EN 14785 for residential space heating appliances fired by wood pellets (EN-14785 October 2006). The schematic of the experimental setup for the emission measurements is shown in Figure 1.

Two experiments (A and B) in part load and Four experiments (C, D, E and F) in nominal load output were conducted for the emissions measurements from a bottom feed pellet stove. The stove was operated in different fan speeds, which regulate air flow into the combustion chamber. Experiments A and B were operated with low speed fan at $900 \mathrm{rpm}, \mathrm{C}$ and D with medium speed fan at $1250 \mathrm{rpm}, \mathrm{E}$ and $\mathrm{F}$ with high speed fan at $1400 \mathrm{rpm}$. Fan speed settings of each experiment are presented in Table 1. The wood pellets are transported through two screws from the pellet storage hopper to the burner cup. The rotation of screw-1 connected to the pellet storage hopper was $1.6 \mathrm{sec} / 6 \mathrm{sec}$ for the part load measurements, while $3.2 \mathrm{sec} / 6 \mathrm{sec}$ for the nominal load experiments. Screw-2 connected to the burner cup was operated at $2 \mathrm{rpm}$ for all the experiments. The heat output of the stove was modified by controlling the rotation of screw-1, which controls the fuel supply.

Emissions from each combustion experiments were evaluated at three combustion phases: start-up, combustion and burnout phase. The start-up phase is the time period commencing after the ignition and lasts until the emission concentrations reaches the same level as in stationary operation. This phase takes about 2025 minutes to complete. The combustion phase is next to the start-up, when the combustion is stable. This phase usually operates several hours. The burnout phase starts with an abrupt rise of $\mathrm{CO}$ emissions followed by a slow decrease and continues until the combustion is completed. This phase takes about 30-50 minutes to complete.

Table 1

Fan speed settings for the different experiments

\begin{tabular}{ccc}
\hline Experiments & Stove load & $\begin{array}{c}\text { Fan speed } \\
\text { (rpm) }\end{array}$ \\
\hline A & Part Load & Low, 900 \\
B & Part load & Low, 900 \\
C & Nominal load & Medium, 1250 \\
D & Nominal Load & Medium, 1250 \\
E & Nominal load & High, 1400 \\
F & Nominal Load & High, 1400 \\
\hline
\end{tabular}

The burnout phase was started in this study, after 4-5 hrs stable operation of the main combustion phase. Firstly, the rotation of screw-1 was stopped to discontinue fuel supply from the pellet storage hopper and to avoid back combustion. Then, fuels remaining in the tube of screw-2 were transported to the burner cup. Finally, screw-2 was stopped, after finishing the combustion of those fuels. Operation of both screws was performed through an electronic control unit.

\subsection{Fuel characteristics}

The elemental composition, moisture content and lower heating value (LHV) of the commercial pellets used in the combustion experiments are presented in Table 2. The pellets are made from soft wood, certified by DINPlus standard and available in the European market.

Table 2

Chemical properties of the pellet used in the combustion experiments

\begin{tabular}{lll}
\hline Parameter & $\begin{array}{c}\text { Commercial } \\
\text { pellets }\end{array}$ & DINplus \\
\hline Length $(\mathrm{mm})$ & $<45$ & $<45$ \\
Diameter (mm) & $6.06 \pm 0.1$ & $6 \pm 0.5$ \\
Durability (\%) & 98.9 & $>97.7$ \\
Fine content (\%) & 0.13 & $<1$ \\
Volumetric mass $\left(\mathrm{kg} / \mathrm{m}^{3}\right)$ & 675 & $>650$ \\
LHV (MJ/kg) & 18.7 & $>16.9$ \\
Moisture (\%) & 8.6 & 10 \\
Ash (wt \%) & 0.3 & 0.7 \\
C (wt \%) & 49.1 & - \\
H (wt \%) & 5.8 & - \\
O (wt \%) & 44.8 & - \\
\hline
\end{tabular}

\subsection{Combustion appliance}

The combustion appliance used in the experiments was a bottom feed pellet stove with a nominal heat output of $5 \mathrm{~kW}$. The pellet stove was setup on a balance to monitor the fuel consumption. The pellet stove is equipped with an 
internal pellet storage, where the pellets are supplied through two screws into the burner cup. The combustion takes place in the burner cup. A step motor is used to supply the pellet into the combustion chamber. The combustion air consisting of primary and secondary air is supplied through the holes under the grid of the burner cup. The air supply is fan assisted and depends upon the selected thermal output. A short cleaning period is set to occur every 30 minutes in the stove. During cleaning, the fuel supply decreases and the air supply increases for 1 minute, removing the ash gathered on the grid. The flame of the stove is upwards and can be seen from the front side of the stove, which is covered with a high temperature transparent glass window. The top of the combustion chamber is equipped with the baffle plate made of vermiculite materials and the sides of refractory ceramic bricks made of calcium silicate. The flue gases are drawn out by an exhaust fan. Before starting each experiment, the grid was cleaned.

\subsection{Gaseous emissions measurement}

A partial flow from the stack at about $2 \mathrm{~m}$ height from the pellet stove was withdrawn through an externally insulated steel probe of $12 \mathrm{~mm}$ diameter. The CO emissions were analyzed continuously from the flue gas by a Siemens Ultramat 6 gas analyzer, $\mathrm{CO}_{2}$ and $\mathrm{O}_{2}$ concentrations were measured continuously using a Horiba PG-250 gas analyzer. Both gas analyzers cannot withstand the hot and humid flue gases for direct analysis. Before the analyzers, the flue gas samples passed through the chiller to remove moisture and to cool down the gas. The gas analysers were calibrated with an appropriate gas mixture, before and after each combustion experiment. The measurement principles of the gas analysers were galvanic analyzer for $\mathrm{O}_{2}$ and non-dispersive infra-red for $\mathrm{CO}, \mathrm{CO}_{2}$. The analyzers have the measurement error of $\pm 2 \%$ full scale in linearity and $\pm 0.5 \%$ full scale in repeatability. Temperature of the indoor air and flue gas in the stack were measured by the K-type thermocouples.

\subsection{Particle mass measurements with the DINplus device}

Two experiments ( $\mathrm{E}$ and $\mathrm{F}$ ) in nominal load output were performed for total particle mass concentration measurements from the undiluted flue gas in the stack in the main combustion phase according to the gravimetric method described in DINplus certification DIN EN-13240 (Gesellschaft 2011). The sampling probe had a diameter of $8 \mathrm{~mm}$ that widened to $9.74 \mathrm{~mm}$ at the inlet opening of the probe. The WÖHLER-Staubmessgerät SM 96 instrument was used for sampling to allow a flue gas volume of $270 \pm 27$ litres to be sampled during a period of 30 minutes. The probe was positioned in the centre of the cross section of the stack. The sampling probe design enabled the capture of particles on a filter, right at the sampling point to avoid any prior-sampling condensation. The used glass microfiber filters had a separation capacity of at least $99.95 \%$ with $0.3 \mu \mathrm{m}$ Di-n-Octyl Phthalate (DOP) smoke particles. Each measurement, filter was inserted into the filter mounting at the end of sample collection tube. The filters were dried for at least 1 hour at $105{ }^{\circ} \mathrm{C}$ in an Air Concept Firlabo oven before and after the sampling, to achieve mass consistency and were weighed afterwards with a balance with $\pm 0.1 \mathrm{mg}$ accuracy.

\subsection{Representative total average emissions overtime}

The total emissions depend on the relative duration of startup, combustion and burnout phases, with a combustion phase which usually takes several hours. If the combustion phase is longer, the total emission especially for CO is smaller and vise versa. Since these times are not identical in all the experiments, the representative average will be based on typical times. Representative times are set for three phases to 20,240 and 30 minutes respectively. The representative total average $\mathrm{CO}$ emissions over time for a complete combustion cycle are calculated by the following formula (Obaidullah 2014).

$$
\text { Total emissions }=\frac{t_{\mathrm{SP}}}{t_{\mathrm{TC}}} \cdot E_{S P}+\frac{t_{\mathrm{CP}}}{t_{\mathrm{TC}}} \cdot E_{\mathrm{CP}}+\frac{t_{\mathrm{BP}}}{t_{\mathrm{TC}}} \cdot E_{\mathrm{BP}}
$$

where:

$t$ SP is the duration of the startup phase, $(20 \mathrm{~min})$ $t_{\text {CP }}$ is the duration of the combustion phase, (240 min) $t_{\mathrm{BP}}$ is the duration of the burnout phase, (30 min) $t_{\mathrm{TC}}$ is the duration of the total cycle, (290 min)

$E_{\mathrm{SP}}$ is the emissions from the startup phase $\left(\mathrm{mg} / \mathrm{Nm}^{3}\right)$

$E_{\text {CP }}$ is the emissions from the combustion phase $\left(\mathrm{mg} / \mathrm{Nm}^{3}\right)$

$E_{\mathrm{BP}}$ is the emissions from the burnout phase $\left(\mathrm{mg} / \mathrm{Nm}^{3}\right)$

\subsection{Combustion efficiency according to the standard}

This study used the indirect method to calculate combustion efficiency of the pellet stove using the EN 13229 standard related to the small scale heating appliances. The combustion efficiency and the different losses were calculated by using the following formulas as described in the European standard EN 13229 (EN-13229 June 2002).

$$
\begin{aligned}
\eta & =100-\left(q_{\mathrm{a}}+q_{\mathrm{b}}+q_{\mathrm{r}}\right) \\
q_{a} & =100 \times \frac{Q_{a}}{L H V} \\
q_{b} & =100 \times \frac{Q_{b}}{\mathrm{LHV}} \\
q_{r} & =100 \times \frac{Q_{r}}{\mathrm{LHV}}
\end{aligned}
$$

where:

$q_{\mathrm{a}}$ is the proportion of the losses through sensible heat in the flue gases, $Q_{\mathrm{a}}$

$q_{\mathrm{b}}$ is the proportion of the losses through chemical heat in the flue gases, $Q_{\mathrm{b}}$

$q_{\mathrm{r}}$ is the proportion of the heat losses through combustible constituents in the residues, $Q_{\mathrm{r}}$

LHV is the Lower heating value of the fuel $(\mathrm{kJ} / \mathrm{kg})$

$Q_{\mathrm{a}}$ is the thermal heat losses in the flue gas, referred to the unit mass of the experiment fuel $(\mathrm{kJ} / \mathrm{kg})$

$Q_{\mathrm{b}}$ is the chemical heat losses in the flue gas, referred to the unit mass of the experiment fuel $(\mathrm{kJ} / \mathrm{kg})$

$Q_{\mathrm{r}}$ is the heat losses through the combustible constituents in residues, referred to the unit mass of the experiment fuel $(\mathrm{kJ} / \mathrm{kg})$

\subsection{Uncertainty analysis}

Standard uncertainties were calculated from the mean values of each measurement taken over a period of time. 
Uncertainty for each relevant component to the experiments was calculated using the formulas as follows (Bell, 2001; Chin et al., 2011; Taylor, 1997):

$$
\begin{aligned}
& \text { Uncertainty }=\sqrt{(\text { Instrumental error })^{2}+\sigma_{M}{ }^{2}} \\
& \sigma_{M}=\frac{2 * \sigma}{\sqrt{N}} \\
& \sigma=\sqrt{\frac{\sum(\mathrm{x}-\overline{\mathrm{x}})^{2}}{(\mathrm{~N}-1)}}
\end{aligned}
$$

where:

$$
\begin{aligned}
& \sigma_{M} \text { is the standard error of mean } \\
& \sigma \text { is the standard deviation of the repeated } \\
& \text { measurements }
\end{aligned}
$$

$\mathrm{N}$ is the total number of measurements taken $\mathrm{x}$ is the measurement value under consideration.

$\bar{x}$ is the average of all the measurement values
The total uncertainty calculation for the combustion efficiency in an equation with multiple variables was computed using the following formula (Taylor 1997, Chin, Chen et al. 2011).

$$
\begin{gathered}
U_{\eta}= \\
\sqrt{\left(\frac{d \eta}{d T_{g}} * U T_{g}\right)^{2}+\left(\frac{d \eta}{d T_{a}} * U T_{a}\right)^{2}+\left(\frac{d \eta}{d C O} * U C O\right)^{2}+\left(\frac{d \eta}{d C O_{2}} * U C O_{2}\right)^{2}}
\end{gathered}
$$

\section{Where:}

$U_{\eta}$ is the total uncertainty for the combustion efficiency

$U T_{\mathrm{g}}$ is the uncertainty of the stack temperature

$U T_{\mathrm{a}}$ is the uncertainty of the room temperature

$U C O$ is the uncertainty of the $\mathrm{CO}$ emissions

\begin{tabular}{|c|c|c|c|c|}
\hline Type of installation & $\begin{array}{l}\text { European } \\
\text { standard }\end{array}$ & $\begin{array}{c}\mathrm{CO} \\
\left(\mathrm{mg} / \mathrm{Nm}^{3}\right)\end{array}$ & $\begin{array}{l}\text { PM limits } \\
\left(\mathbf{m g} / \mathrm{Nm}^{3}\right)\end{array}$ & Efficiency (\%) \\
\hline Log boiler, manual loading & $\begin{array}{l}\text { EN303-5 } \\
\text { EN12809 }\end{array}$ & 600 & 50 & 83 \\
\hline Densified wood boiler & $\begin{array}{l}\text { EN303-5 } \\
\text { EN12809 }\end{array}$ & 3001 & 60 & 85 \\
\hline Wood pellet boiler & $\begin{array}{l}\text { EN303-5 } \\
\text { EN12809 }\end{array}$ & 2501 & 40 & 85 \\
\hline Space heating with solid fuels & EN13240 & 3000 & 100 & 75 \\
\hline Centralized furnace for solid fuels & EN12815 & 3000 & 100 & 75 \\
\hline Space heating using wood pellet fuels & EN14785 & 500 & 40 & 80 \\
\hline Chimney insert-open chimney for solid fuels & EN13229 & 1500 & 75 & 75 \\
\hline
\end{tabular}

$\mathrm{UCO}_{2}$ is the uncertainty of the $\mathrm{CO}_{2}$ emissions

and $\mathrm{d} \eta / \mathrm{dT} \mathrm{T}_{\mathrm{g}}, \mathrm{d} \eta / \mathrm{dCO}_{2}$ are the partial derivatives of combustion efficiency with respect to stack temperature and $\mathrm{CO}_{2}$ emissions.

Table 3

Limit values on CO, PM emissions and combustion efficiency for small scale combustion units (13 vol \% $\mathrm{O}_{2}$ concentrations) (Belgium, October 2010; Mudgal, December 2009; Villeneuve et al., 2012)

\section{Existing Limit Values of CO, PM and Efficiency}

The European Union (EU) has established sustainability objectives for the development of the biomass industry in order to develop this industry without creating an overall environmental negative impact associated with biomass resources. In order to meet these binding targets, each member state must establish its own specific plan. Moreover, these targets must be met by respective environmental standards for biomass combustion. European clean air requirements are getting stricter on particulate matter (PM), forcing the European countries to reduce its different sources to meet this requirement. Table 3 shows that CO, PM emissions expressed in $\mathrm{mg} / \mathrm{Nm}^{3}$ and combustion efficiency limits in Europe for small scale combustion units $(\leq 300 \mathrm{~kW})$. The limit values are applicable for stable combustion

\section{Results and Discussions}

A total of six combustion experiments on gaseous and particle emissions from a bottom feed pellet stove were conducted. Experiments A and B were conducted with part load heat output of $2.5 \mathrm{~kW}$, while four experiments C, D, $\mathrm{E}$ and $\mathrm{F}$ were in the nominal load output at $5 \mathrm{~kW}$. As the objectives of this study was to evaluate the emissions from different combustion phases of each experiment, the emission results from each experiment are presented as the start-up, the combustion and the burnout phases. Gaseous emissions of $\mathrm{CO}, \mathrm{CO}_{2}, \mathrm{O}_{2}$, excess air from three phases are presented in Table 4 .

The air excess $(\lambda)$ obtained from all the experiments in the combustion phase of the nominal load output (experiments $\mathrm{C}$ to $\mathrm{F}$ ) varied between 2.1 to 2.9 , which is lower than the part load output (4.2 to 4.7) experiments. Sampling duration of each phase of the combustion experiment is listed in Table 4 . The performance analysis in terms of combustion efficiency together with different losses is presented in Table 5. Since the combustion process varies over time, the presented standard deviation $( \pm)$ also describes the variation of the process 
Table 4

Gaseous emissions in the flue gas measured from the combustion experiments

\begin{tabular}{|c|c|c|c|c|c|c|c|}
\hline Experiments & FS & Phase & $\begin{array}{l}\mathrm{O}_{2} \text { conc } \\
\text { (vol. \%) }\end{array}$ & $\begin{array}{l}\mathrm{CO}_{2} \text { conc } \\
\text { (vol. \%) }\end{array}$ & $\begin{array}{l}\mathrm{CO} \mathrm{mg} / \mathrm{Nm}^{3} \\
\left(13 \% \mathrm{O}_{2}\right)\end{array}$ & $\boldsymbol{\lambda}$ & $\begin{array}{l}\text { D } \\
\text { hr:min }\end{array}$ \\
\hline \multicolumn{8}{|c|}{ Part load output $(2.5 \mathrm{~kW})$} \\
\hline \multirow{4}{*}{ A } & \multirow{4}{*}{$\mathrm{L}$} & SP & $19.7 \pm 0.2$ & $1.4 \pm 0.2$ & $1711 \pm 157$ & 16.9 & $0: 20$ \\
\hline & & $\mathrm{CP}$ & $16.5 \pm 0.2$ & $4.3 \pm 0.3$ & $1451 \pm 178$ & 4.7 & $4: 15$ \\
\hline & & $\mathrm{BP}$ & $19.3 \pm 0.1$ & $1.6 \pm 0.1$ & $10904 \pm 474$ & 12.7 & $0: 29$ \\
\hline & & Total & $16.8 \pm 0.2$ & $3.9 \pm 0.2$ & $2447 \pm 207$ & 5.18 & $5: 34$ \\
\hline \multirow{4}{*}{$\mathrm{B}$} & \multirow{4}{*}{$\mathrm{L}$} & $\mathrm{SP}$ & $19.2 \pm 0.2$ & $1.8 \pm 0.2$ & $2372 \pm 152$ & 12.1 & $0: 20$ \\
\hline & & $\mathrm{CP}$ & $15.8 \pm 0.3$ & $4.9 \pm 0.3$ & $1215 \pm 150$ & 4.2 & $5: 35$ \\
\hline & & $\mathrm{BP}$ & $19.5 \pm 0.2$ & $1.4 \pm 0.2$ & $10502 \pm 416$ & 14.5 & $0: 29$ \\
\hline & & Total & $16.0 \pm 0.3$ & $4.7 \pm 0.3$ & $2247 \pm 178$ & 4.2 & $6: 24$ \\
\hline \multicolumn{8}{|c|}{ Nominal load output $(5 \mathrm{~kW})$} \\
\hline \multirow{4}{*}{$\mathrm{C}$} & \multirow{4}{*}{$\mathrm{M}$} & SP & $19.7 \pm 0.2$ & $1.3 \pm 0.2$ & $908 \pm 250$ & 16.9 & $0: 19$ \\
\hline & & $\mathrm{CP}$ & $13.2 \pm 0.6$ & $7.5 \pm 0.6$ & $145 \pm 92.4$ & 2.7 & $4: 30$ \\
\hline & & $\mathrm{BP}$ & $19.8 \pm 0.2$ & $1.1 \pm 0.2$ & $11016 \pm 354$ & 18.7 & $0: 30$ \\
\hline & & Total & $14.1 \pm 0.4$ & $6.6 \pm 0.4$ & $1322 \pm 130$ & 3.1 & $5: 19$ \\
\hline \multirow{4}{*}{$\mathrm{D}$} & \multirow{4}{*}{$\mathrm{M}$} & $\mathrm{SP}$ & $18.6 \pm 0.4$ & $2.4 \pm 0.4$ & $1014 \pm 133$ & 9.1 & $0: 20$ \\
\hline & & $\mathrm{CP}$ & $13.8 \pm 0.5$ & $6.9 \pm 0.5$ & $132 \pm 59.2$ & 2.9 & $3: 50$ \\
\hline & & $\mathrm{BP}$ & $20.1 \pm 0.1$ & $0.9 \pm 0.1$ & $11256 \pm 331$ & 24.0 & $0: 28$ \\
\hline & & Total & $14.9 \pm 0.4$ & $5.8 \pm 0.4$ & $1343 \pm 92$ & 3.5 & $4: 38$ \\
\hline \multirow{4}{*}{$\mathrm{E}$} & \multirow{4}{*}{$\mathrm{H}$} & $\mathrm{SP}$ & $17.7 \pm 0.5$ & $3.2 \pm 0.5$ & $2275 \pm 331$ & 6.5 & $0: 18$ \\
\hline & & $\mathrm{CP}$ & $11.0 \pm 1.0$ & $9.7 \pm 0.9$ & $50.7 \pm 7.8$ & 2.1 & $5: 45$ \\
\hline & & $\mathrm{BP}$ & $18.4 \pm 0.6$ & $2.4 \pm 0.6$ & $3531 \pm 361$ & 8.5 & $0: 50$ \\
\hline & & Total & $12.1 \pm 0.7$ & $8.6 \pm 0.7$ & $564 \pm 67$ & 2.4 & $6: 53$ \\
\hline \multirow{4}{*}{$\mathrm{F}$} & \multirow{4}{*}{$\mathrm{H}$} & $\mathrm{SP}$ & $17.9 \pm 0.3$ & $2.9 \pm 0.3$ & $2294 \pm 227$ & 6.9 & $0: 17$ \\
\hline & & $\mathrm{CP}$ & $11.4 \pm 0.7$ & $9.2 \pm 0.7$ & $51.2 \pm 28.9$ & 2.2 & $4: 40$ \\
\hline & & $\mathrm{BP}$ & $18.7 \pm 0.7$ & $2.2 \pm 0.6$ & $3712 \pm 337$ & 9.4 & $0: 52$ \\
\hline & & Total & $12.6 \pm 0.6$ & $7.9 \pm 0.6$ & $585 \pm 78$ & 2.5 & $5: 49$ \\
\hline
\end{tabular}

$\mathrm{FS}=$ fan speed, $\mathrm{L}=$ low, $\mathrm{M}=$ medium, $\mathrm{H}=$ high, $\mathrm{SP}=$ start-up phase, $\mathrm{CP}=$ combustion phase, $\mathrm{BP}=$ burnout phase, Total CO emissions were calculated based on equation $1, \lambda=$ excess air, $\mathrm{D}=$ duration

Table 5

Combustion efficiency with different losses obtained from all the measurements

\begin{tabular}{|c|c|c|c|c|c|c|}
\hline \multirow{2}{*}{$\begin{array}{l}\text { Parameter } \\
\text { Experiments }\end{array}$} & \multicolumn{2}{|c|}{ Part load output (2.5 kW) } & \multicolumn{4}{|c|}{ Nominal load output (5 kW) } \\
\hline & $\mathrm{A}$ & $\mathrm{B}$ & $\mathrm{C}$ & $\mathrm{D}$ & $\mathrm{E}$ & $\mathrm{F}$ \\
\hline Fan speed & Low & Low & $\mathrm{M}$ & $\mathrm{M}$ & High & High \\
\hline $\mathrm{FC}(\mathrm{kg} / \mathrm{hr})$ & 0.7 & 0.7 & 1.4 & 1.3 & 1.2 & 1.2 \\
\hline$T_{\mathrm{a}}\left({ }^{\circ} \mathrm{C}\right)$ & 19.7 & 23.9 & 23.9 & 22.2 & 21.6 & 21.7 \\
\hline$T_{\mathrm{g}}\left({ }^{\circ} \mathrm{C}\right)$ & $64 \pm 7.3$ & $63 \pm 7.1$ & $84 \pm 16$ & $85 \pm 18$ & $101 \pm 21$ & $101 \pm 22$ \\
\hline$C_{\text {pmd }}(\mathrm{kJ} / \mathrm{kgK})$ & 1.32 & 1.32 & 1.33 & 1.32 & 1.34 & 1.33 \\
\hline$C_{\mathrm{pmH} 2 \mathrm{O}}(\mathrm{kJ} / \mathrm{kgK})$ & 1.5 & 1.5 & 1.5 & 1.5 & 1.5 & 1.5 \\
\hline$Q_{\mathrm{a}}(\mathrm{kJ} / \mathrm{kg})$ & 1305 & 970 & 1192 & 1404 & 1254 & 1346 \\
\hline$q_{\mathrm{a}}(\%)$ & 6.9 & 5.2 & 6.4 & 7.5 & 6.7 & 7.2 \\
\hline$Q_{\mathrm{b}}(\mathrm{kJ} / \mathrm{kg})$ & 201 & 146 & 38.3 & 45.1 & 23.6 & 26.9 \\
\hline$q_{\mathrm{b}}(\%)$ & 1.1 & 0.8 & 0.21 & 0.24 & 0.13 & 0.14 \\
\hline$q_{\mathrm{r}}(\%)$ & 0.2 & 0.2 & 0.2 & 0.2 & 0.2 & 0.2 \\
\hline Total heat loss (\%) & 8.2 & 6.2 & 6.8 & 7.9 & 7 & 7.5 \\
\hline $\mathrm{PO}(\mathrm{kW})$ & 3.2 & 3.3 & 6.7 & 6.2 & 5.8 & 5.6 \\
\hline$\eta(\%)$ & 91.8 & 93.8 & 93.2 & 92.1 & 93 & 92.5 \\
\hline
\end{tabular}

$\mathrm{FC}=$ Fuel consumption, $\mathrm{T}_{\mathrm{a}}=$ ambient temperature, $T_{\mathrm{g}}=$ flue gas temperature in stack, PO = power output, $\eta=$ combustion efficiency calculated by the standard EN $13229, \mathrm{M}=$ medium 


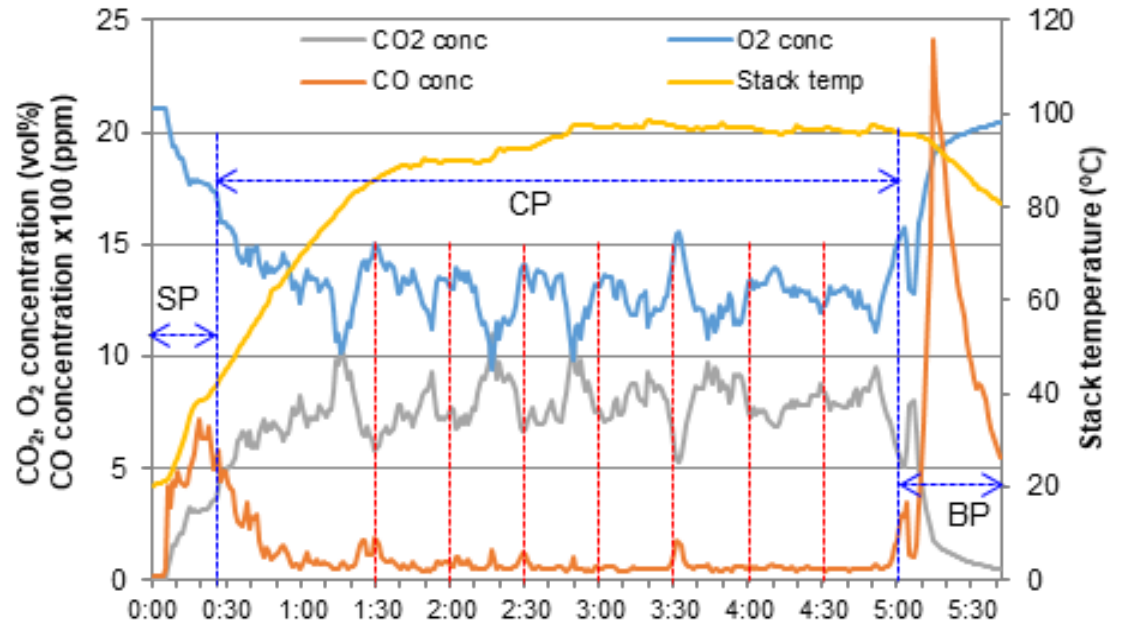

Measurement time (hr:min)

Fig. 1 Typical variation of $\mathrm{CO}_{2}, \mathrm{O}_{2}, \mathrm{CO}$ concentration and stack temperature obtained from Experiment $\mathrm{C}$, $\mathrm{SP}=$ startup phase, $\mathrm{CP}=$ combustion phase (stationary operation), $\mathrm{BP}=$ burnout phase. The red dash lines indicate the time for ash removal by increasing air supply.

\subsection{Gaseous emissions from combustion experiments}

The composition of the flue gas is very complicated and depends on various factors such as the fuel type, combustion condition and the flow rate of the combustion air. In the combustion experiments, two gas compositions $\left(\mathrm{CO}_{2}\right.$ and $\left.\mathrm{O}_{2}\right)$ were measured continuously using a Horiba PG-250 gas analyzer, while the CO concentrations were measured continuously by a Siemens Ultramat 6 gas analyzer. $\mathrm{NO}_{\mathrm{x}}$ emission measurements were not performed from the pellet stove, because the $\mathrm{NO}_{\mathrm{x}}$ cell of the analyzer was not operational.

\subsubsection{Time series of gaseous emissions}

Figure 1 shows the typical variation of concentration of $\mathrm{CO}_{2}, \mathrm{O}_{2}, \mathrm{CO}$ and stack temperature recorded during startup, combustion and burnout phases of Experiment $\mathrm{C}$ operated in nominal load condition. It can be seen from Figure 3 that at the startup phase the concentrations of CO sharply increases and the temperature of the flue gas starts to increase. After the ignition, the combustion phase begins with sufficiently lower $\mathrm{CO}$ concentration and higher stack temperature. At the end, the burnout phase starts with an abrupt rising of $\mathrm{CO}$ emissions followed by decreasing of $\mathrm{CO}$ emissions and stack temperature. It can also be seen in Figure 1 that the $\mathrm{O}_{2}$ and $\mathrm{CO}_{2}$ concentrations fluctuate during the combustion phase. This is probably caused by the setting of short ash removal for every 30 minutes interval, which decreases the fuel supply and increases the air supply for one minute.

\subsection{2. $\mathrm{CO}$ emission}

The CO emissions obtained from the startup, combustion, burnout phase of all the experiments are presented in Figures 2, 3 and 4 respectively. The error bars present the uncertainty of the measurements calculated as the formulas presented in section 2.7. The $\mathrm{CO}$ emission values presented here are normalized with $13 \%$ dry oxygen content. It is clearly observed from all the experiments that $\mathrm{CO}$ emissions in the burnout phase were significantly higher than that in the startup phase followed by the combustion phase. The air excess $(\lambda)$ in the burnout phase for all the experiments was quite higher than that in the other two phases. High excess air in the burnout phase cools the combustion chamber, resulting in high $\mathrm{CO}$ emissions.

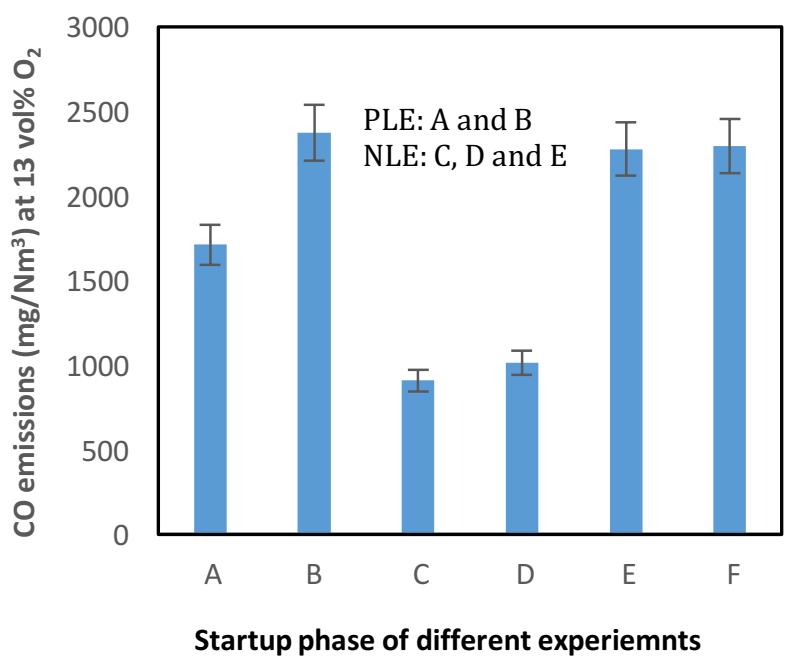

Fig. $2 \mathrm{CO}$ emissions obtained from the startup phase of all the experiments, A, B, C, D, E and F are the combustion experiments, PLE $=$ Part load experiments, NLE $=$ Nominal load experiments

It can be seen from Figure 2, that the $\mathrm{CO}$ emissions obtained from the startup phase of the part load heat output varied from $1710 \mathrm{mg} / \mathrm{Nm}^{3}$ to $2370 \mathrm{mg} / \mathrm{Nm}^{3}$ for Experiments A to B, while in the nominal load heat output varied from $50 \mathrm{mg} / \mathrm{Nm}^{3}$ to $145 \mathrm{mg} / \mathrm{Nm}^{3}$ for the 
Experiments $\mathrm{C}$ to $\mathrm{F}$. The duration of startup phase is about 20 minutes for all the experiments. The stove operated in the medium speed fan gives lower CO emission in the startup phase. However, $\mathrm{CO}$ emissions in the startup phase for the experiments $\mathrm{E}$ and $\mathrm{F}$ were higher than the measurements $\mathrm{C}$ to $\mathrm{D}$. At the startup phase, the combustion temperature was not high enough to provide sufficient burnout condition. This might be a reason for increasing $\mathrm{CO}$ emissions during the startup phase.

Figure 3 shows the comparison of $\mathrm{CO}$ emissions obtained from the main combustion phase of all the experiments with the required limit value of the NBN EN 14785 standard and the literature (Verma, Bram et al. 2011). CO emissions in $\mathrm{Y}$ axis is presented in logarithm scale. The $\mathrm{CO}$ emissions from the medium and high speed fan stove operated with nominal load output satisfied the required limit value of the NBN EN 13229 standard and lower than other work (Verma et al. 2011). CO emissions obtained from the low speed fan operated with part load heat output meet not satisfied the required limit value of the standard.

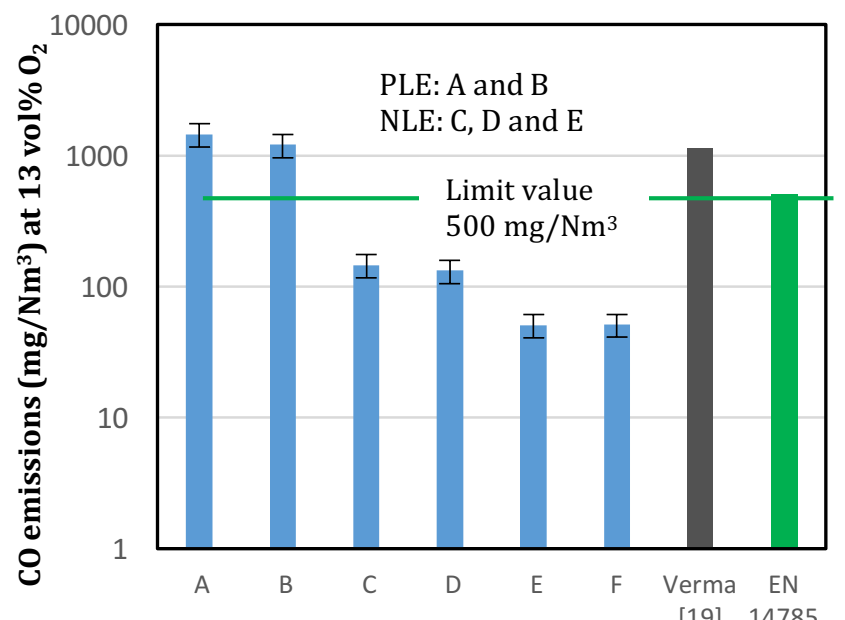

Combustion phase of different experiemnts and the standard

Fig. 3 Comparison of CO emissions obtained from the combustion phase of all experiments with the standard, A, B, C, D, E and F are the combustion experiments, PLE = Part load experiments, NLE $=$ Nominal load experiments

It can also be seen from Figure 3 that the $\mathrm{CO}$ emissions obtained from the main combustion phase of the part load heat output varied from $1215 \mathrm{mg} / \mathrm{Nm}^{3}$ to $1450 \mathrm{mg} / \mathrm{Nm}^{3}$ for Experiments $\mathrm{A}$ and $\mathrm{B}$, while in the nominal load heat output varied from $50 \mathrm{mg} / \mathrm{Nm}^{3}$ to $145 \mathrm{mg} / \mathrm{Nm}^{3}$ for the Experiments $\mathrm{C}$ to $\mathrm{F}$. The duration of the main combustion phase varied from $3 \mathrm{hr} 50 \mathrm{~min}$ to $5 \mathrm{hr} 45 \mathrm{~min}$ for all the measurements. The lower $\mathrm{CO}$ emissions obtained from the stove operated with high speed fan than the medium speed fan followed by the low speed fan. Higher CO emission in the part load experiments was probably due to the higher air excess factor (about $\lambda=4.35$ ) obtained in low speed fan, which gives lower combustion temperature, leading to high CO emissions. On the other hand, a correctly matched air excess factor (about $\lambda=2.5$ ) for the medium and high-speed fan operated experiments created favorable combustion conditions, leading to less $\mathrm{CO}$ emissions. Besides, the average flue gas temperature was much lower in the low speed fan $\left(64^{\circ} \mathrm{C}\right)$ operated experiments than the medium speed $\left(85^{\circ} \mathrm{C}\right)$ and highspeed fan $\left(101^{\circ} \mathrm{C}\right)$.

It can be seen from Figure 4 that Experiments E and $\mathrm{F}$ had the lower $\mathrm{CO}$ emissions in the burnout phase because of the different configuration of the fan speed from other measurements A, B, C and D. Also, the fan speeds for the Experiments $\mathrm{E}$ and $\mathrm{F}$ were higher than the other experiments. This means that sufficient amounts of combustion air were supplied to burn the combustible gases; as a result, CO emissions were lower. Experiments conducted in the high speed fan gives lower CO emission in the this phase.

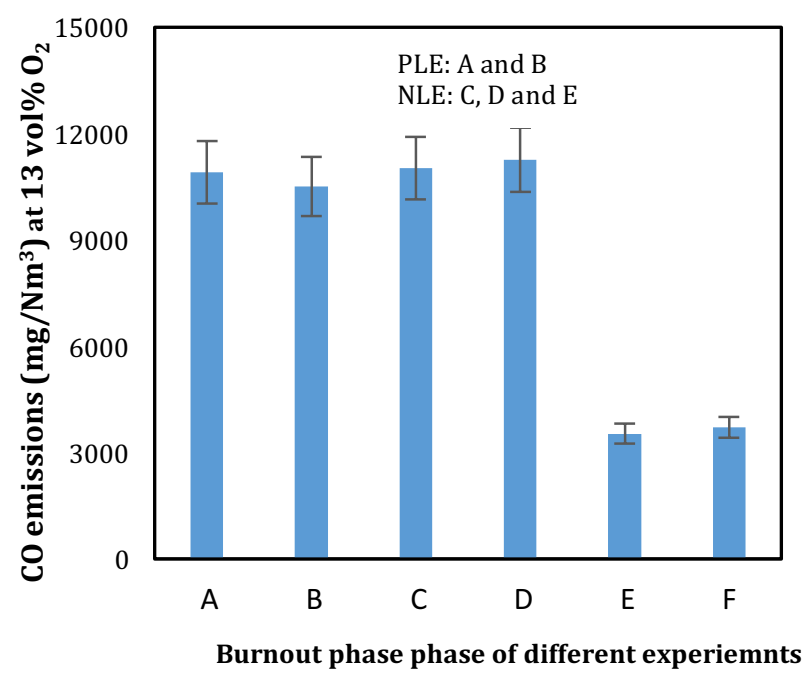

Fig. $4 \mathrm{CO}$ emissions obtained from the burnout phase of all the experiments, A, B, C, D, E and F are the combustion experiments, PLE $=$ Part load experiments, NLE $=$ Nominal load experiments

Figure 5 shows the representative total $\mathrm{CO}$ emissions obtained from all the experiments. The total $\mathrm{CO}$ emissions are relatively higher in part load combustion experiments compared to nominal load output. This was due to the lower combustion temperatures caused by high air excess at the part load combustion experiments (Table 4). The total CO emissions obtained in the part load experiments can be compared with values found in other work. For example, Schmidl et al (2011) investigated gaseous emissions from a $3 \mathrm{~kW}$ pellet stove in part load power output. The $\mathrm{CO}$ emissions in their study were $751 \mathrm{mg} / \mathrm{Nm}^{3}$ which is quite lower than that in our study. The total CO emissions obtained from the nominal load output experiments are higher than other studies. For example, the CO emissions results of Bäfver et al.(2011) investigated from a pellet stove with $5 \mathrm{~kW}$ capacity range between $140 \mathrm{mg} / \mathrm{Nm}^{3}$ to $405 \mathrm{mg} / \mathrm{Nm}^{3}$.

It is clearly observed from Table 4 that that $\mathrm{CO}$ emissions in the burnout phase from all the experiments were significantly higher than that in the startup phase followed by the combustion phase. For example, CO emissions in the burnout phase for Experiments C to D were about 12 fold higher than in the startup phase and 
75 fold higher than in the combustion phase. The air excess $(\lambda)$ in the burnout phase for all the experiments was quite higher than that in the other two phases. High excess air in the burnout phase cools the combustion chamber, resulting in high $\mathrm{CO}$ emissions. It can be mentioned from the experimental results that the impact of higher $\mathrm{CO}$ emissions in the startup and burnout phase has influence on the total $\mathrm{CO}$ emissions.

Several studies show in the literature (Gonzalez et al. 2004, Mediavilla et al. 2009, Tissari et al. 2009) that T-3 control played a key role in combustion optimization and consequently emissions reduction.

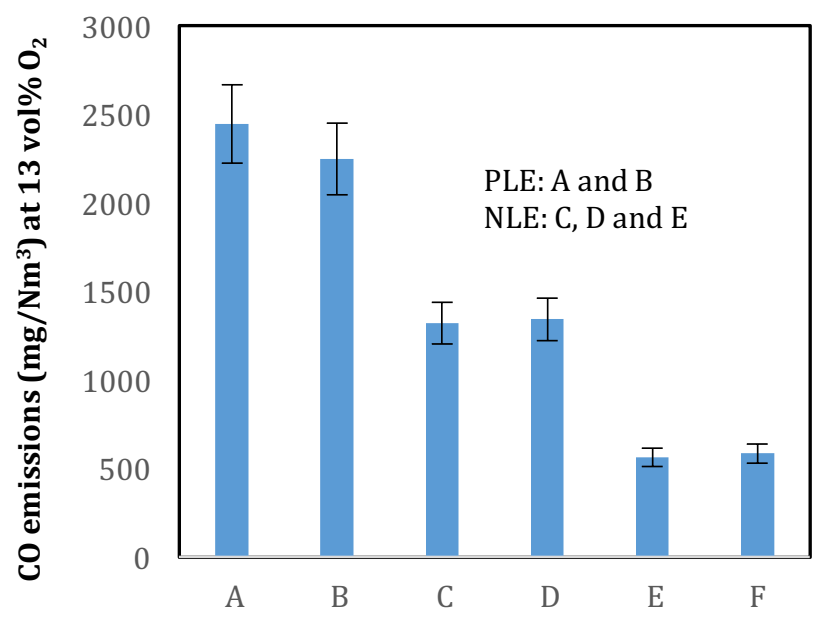

Total cycle of different experiemnts

Fig. 5 Total $\mathrm{CO}$ emissions obtained from all the experiments, $\mathrm{A}, \mathrm{B}, \mathrm{C}, \mathrm{D}, \mathrm{E}$ and $\mathrm{F}$ are the combustion experiments, PLE = Part load experiments, $\mathrm{NLE}=$ Nominal load experiments

The T-3 control stands for high combustion Temperature, Turbulence to mix fuel with necessary oxygen and sufficient residence Time for the combustion products to reach complete combustion). The formation of CO Emissions from a combustion appliance might result from low combustion temperature, insufficient oxygen, poor mixing of fuel with the combustion air and/or too short residence time of the combustion gases in the combustion zone factors or a combination of these factors (Tissari et al. 2009, Roy and Corscadden 2012).

CO emissions from small scale biomass combustion appliances can be reduced using flue gas cleaning technologies such as catalytic combustors, which consist of a metal wire mesh covered with catalytic material, platinum and palladium. The catalytic combustors are attached to a steel frame which can be inserted compactly inside the stack through an opening. Smoke gases pass through the catalytic element and ignite at a much lower temperature around $250{ }^{\circ} \mathrm{C}$. The result is that harmful substances are more completely burned. The fuel produces more heat through an extended clean burn. Hukkanen et al. (2012) investigated reduction of gaseous emissions using a catalytic combustor from a $15 \mathrm{~kW}$ stove. Their results show that reductions of $\mathrm{CO}$ reached about $25 \%$ during the whole combustion cycle. Such gas cleaning systems are however quite expensive for small scale applications.

\section{$4.2 \mathrm{O}_{2}$ and $\mathrm{CO}$ concentrations as function of temperature}

Figure 6 illustrates the concentrations between the combustion chamber temperature, flue gas oxygen concentrations and $\mathrm{CO}$ concentrations. The temperature was measured at the top of the combustion chamber using a thermocouple. The startup phase is not included in the figure as the temperature was quite lower. In the burnout phase, the oxygen and $\mathrm{CO}$ concentrations show irregular pattern (looks two lines), where values are jumping between low and high concentrations. This is probably due to unsteady combustion and little fire over time. The figure indicates that $\mathrm{CO}$ formation is higher at the slow burning rate of the fuel. It can be seen that there is a very good correlation between them. A similar trend is also observed for the $\mathrm{O}_{2}$ concentration with a very good correlation with the combustion chamber temperature.

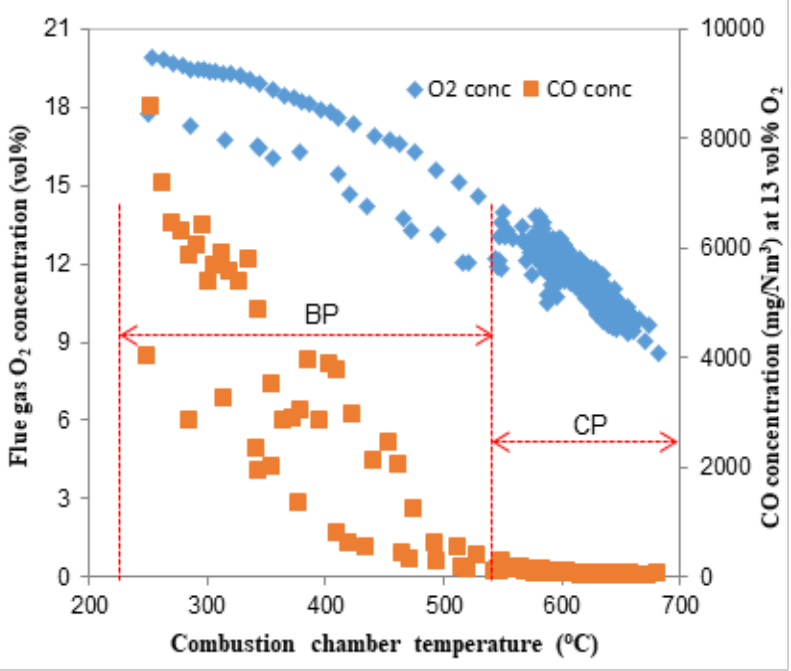

Fig. $6 \mathrm{O}_{2}$ and $\mathrm{CO}$ concentrations as function of the combustion chamber temperature obtained from Experiment $\mathrm{F}$, $\mathrm{CP}=$ combustion phase, $\mathrm{BP}=$ burnout phase

\subsection{Particle mass concentrations with the DINplus technique}

Particle mass concentrations were measured from the raw sample at the combustion phase of Experiments $\mathrm{E}$ and $\mathrm{F}$ by a WÖHLER-Staubmessgerät SM 96 instrument using the DINplus sampling technique. Particles were sampled for a period of 30 minutes to allow a flue gas volume of $270 \pm 27$ litres. In the DINplus sampling device, the filter catches all the particles larger than $0.3 \mu \mathrm{m}$. Particle mass concentrations were obtained between 15 $\mathrm{mg} / \mathrm{Nm}^{3}$ and $10 \mathrm{mg} / \mathrm{Nm}^{3}$ for Experiments $\mathrm{E}$ and $\mathrm{F}$ respectively. Experiment $\mathrm{F}$ had lower particle mass concentrations than the Experiment E (Figure 9), which represents the better combustion. These particles are known as fly ash particles formed through several pathways in biomass combustion (Heschel et al. 1999, Sippula et al. 2009, Tissari et al. 2009). The particles consist of inorganic, soot and organic particles. The 
inorganic particles are constituted to a large fraction of alkaline salts $\left(\mathrm{K}_{2} \mathrm{SO}_{4}\right.$ and $\left.\mathrm{KCl}\right)$ depending on the fuel composition at favourable combustion conditions, while soot and organic particles are also emitted as solid particles if the combustion conditions are poor.

In addition, the mass concentrations obtained from this study are also very low when comparing with other works. For example, Verma et al (2011). reported $40 \mathrm{mg} / \mathrm{Nm}^{3}$ total mass concentrations from a $40 \mathrm{~kW}$ pellet boiler using the same technique. Another study, Qie et al. (Qiu 2013) reported that particle emissions in a small scale pellet boiler $(50 \mathrm{~kW})$ using a Dust Tank-II Handheld Aerosol Monitor were $73 \mathrm{mg} / \mathrm{Nm}^{3}$. Figure 7 shows the comparison of particle mass concentration obtained from the experiments $\mathrm{E}$ and $\mathrm{F}$ with the required limit value of standard EN14785. The particle mass emissions from all the measurements are much lower than the standard and the other works.

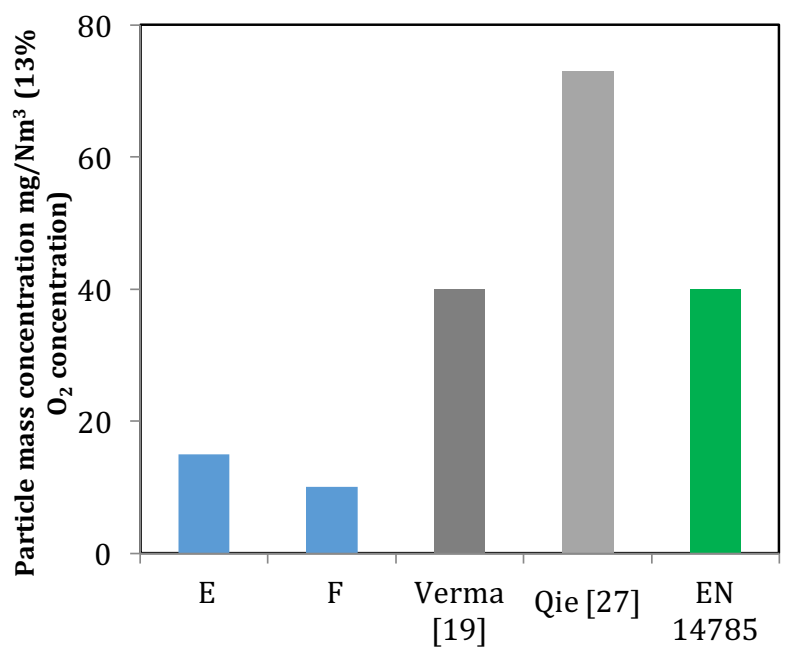

Different experiments, literature and the Standard

Fig. 7 Comparison of particle mass emission obtained from the measurements

The combustion of woody fuels in small scale heating appliances is a major source of fine particle emissions. These appliances are accused of producing harmful particulate pollutants, since they generate significant amounts of particles at low emission heights. Recent findings show that dominating source of $\mathrm{PM}_{2.5}$ from the combustion of solid biomass was about $34 \%$ to the total emissions in EU-27 countries (Cofala and Klimont June 2012). Recent investigations have found that wood combustion contributes more than $20 \%$ of carbonaceous aerosols in France during winter months (Favez, Cachier et al. 2009). Particle mass concentration can be reduced by installing the units of cyclones, wet scrubbers and ESP in the stack. The ESP systems have higher particle separation efficiency than the cyclones and wet scrubbers and use in the EU countries (Obernberger and Mandl December 2011). However, such particle removal technologies are quite expensive for small scale applications.

\subsection{Performance analysis}

The performance analysis in terms of combustion efficiency of the pellet stove was determined using an indirect method according to the standard EN 14785 that takes the thermal, chemical and radiation heat losses into consideration (EN-14785 October 2006). Efficiency is calculated as the difference between energy input and the sum of the losses. The thermal heat loss is calculated on the basis of the difference between the temperature of the flue gas and the room temperature and the specific heat of the flue gas. The chemical heat loss is calculated from the $\mathrm{CO}$ and $\mathrm{CO}_{2}$ concentrations of the flue gas. The radiation heat loss is taken as $0.2 \%$ according to the standard EN 14785. The formulas used for the calculation of the combustion efficiency and the different losses were presented in the Section 2.5.

The combustion efficiency of the pellet stove as a function of different operational loads is compared with the required limit value of the standard NBN EN 14785 and presented in Figure 10.

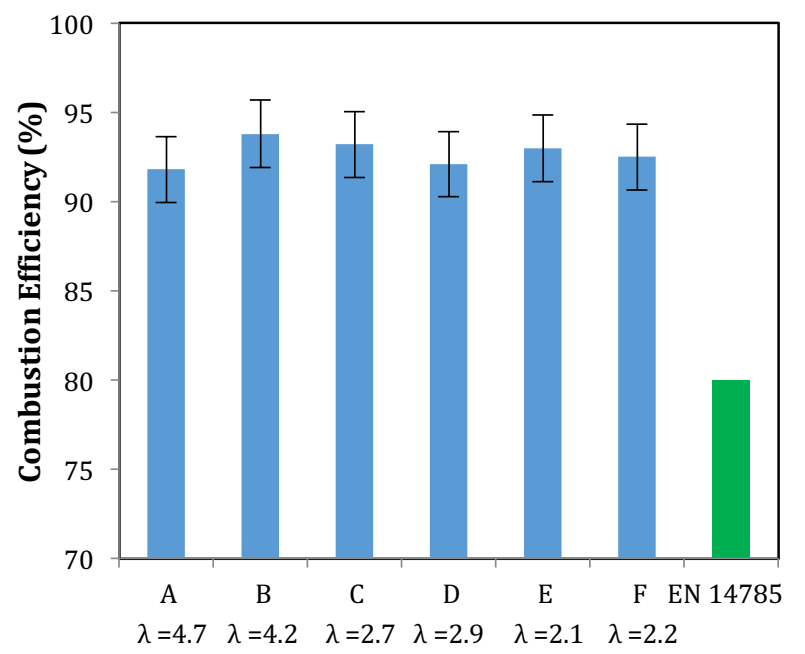

Different Experiments and the Standard

Fig. 8 Combustion efficiency compared with the standard, A, B, $\mathrm{C}, \mathrm{D}, \mathrm{E}$ and $\mathrm{F}$ are the combustion experiments, $\lambda=$ excess air

It can be seen from the figure that all the measurements both from nominal heat and part load output meet the standard. All the experiments have almost similar combustion efficiencies at both operational loads. The average combustion efficiency obtained from all the experiments for the low speed fan, medium speed fan and high-speed fan was $92.8 \pm 1.2 \%, 92.4 \pm 1.1 \%$ and $92.7 \pm 1.2 \%$ respectively. The average thermal heat and chemical heat losses are estimated at $6.05 \%$ and $0.93 \%$ respectively for the low speed fan, $6.95 \%$ and $0.22 \%$ respectively for the medium speed fan and $6.95 \%$ and $0.14 \%$ respectively for the high-speed fan, which influences the variations of the combustion efficiency as seen from Figure 8. Experiment $B$ had the highest combustion efficiency from the part load operated with low speed fan, while Experiments C and E had the higher efficiency from the nominal load output.

The combustion efficiency evaluated from the experiments in nominal load heat output can be compared with other works. For example, Sippula et.al (2007) 
mentioned about $85 \%$ combustion efficiency from a $8 \mathrm{~kW}$ modern pellet stove in standard laboratory condition and Verma et al. (2011) reported $90.7 \%$ combustion efficiency from a modern residential pellet heating system, which are lower than this study.

\section{Conclusions}

Two combustion experiments at part load conditions and four experiments in nominal load with a bottom feed pellet stove were conducted for gaseous and particle mass emissions measurements in a stove manufacturing plant in Belgium. Gaseous emission measurements include CO, $\mathrm{CO}_{2}$ and $\mathrm{O}_{2}$ concentrations were done continuously by gas analyzers and the particle mass concentrations were performed by a WÖHLER-Staubmessgerät SM 96 instrument using the DINplus sampling technique. Performance analysis in terms of combustion efficiency together with different losses is also evaluated. Following conclusions can be made from the results of all the measurements.

- CO emissions in the burnout phase from all the experiments were significantly higher than that in the startup phase followed by the combustion phase. CO emissions in the burnout phase for Experiments $\mathrm{C}$ to $\mathrm{D}$ were about 12 fold higher than in the startup phase and 75 fold higher than in the combustion phase. The air excess $(\lambda)$ in the burnout phase for all the experiments was quite higher than that in the other two phases. The experimental results show that the impact of higher $\mathrm{CO}$ emissions in the startup and burnout phase has influence to increase the total $\mathrm{CO}$ emissions.

- The CO emissions obtained from the main combustion phase of the part load heat output varied from $1215 \mathrm{mg} / \mathrm{Nm}^{3}$ to $1450 \mathrm{mg} / \mathrm{Nm}^{3}$ for Experiments A and B respectively, while in the nominal load heat varied output from $50 \mathrm{mg} / \mathrm{Nm}^{3}$ to $145 \mathrm{mg} / \mathrm{Nm}^{3}$ for the Experiments $\mathrm{C}$ to $\mathrm{F}$ respectively. Experiments conducted in the high speed fan gives lower $\mathrm{CO}$ emission in the this phase. The CO emissions in the burnout phase for Experiments $\mathrm{C}$ to D were about 12 fold higher than in the startup phase and 75 fold higher than in the combustion phase.

- The CO emissions obtained in the main combustion phase from the experiments conducted with high speed fan is lower than the medium speed fan followed by the low speed fan. Higher CO emission in the low speed fan was probably due to the higher air excess factor (about $\lambda=4.35$ ), which gives lower combustion temperature, leading to high CO emissions.

- Particle mass concentrations obtained from the measurements satisfied the required limit value of the standard EN14875. These particles are known as fly ash particles formed through several pathways of biomass combustion. Particle mass concentration can be reduced by installing the units of cyclones, wet scrubbers and ESP in the stack. However, such particle removal technologies are quite expensive for small scale applications.

- The experimental findings indicate that the excess air, combustion temperature, residence time, mixing in the combustion chamber are probably the important factors influencing the overall emissions.

- The average combustion efficiency obtained from all the experiments for the low speed fan, medium speed fan and high speed fan was $92.8 \pm 1.2 \%$, $92.4 \pm 1.1 \%$ and $92.7 \pm 1.2 \%$ respectively. The combustion efficiency obtained from all the experiments satisfied the required limit value of the NBN EN 14785 standard.

- The present study was performed under controlled laboratory conditions. Therefore, the next step is to perform field measurements on gaseous and particle emissions as well as performance analysis. This will reveal the effects of daily life operational practices on the performance of the pellet heating systems.

\section{Acknowledgements}

The author gratefully acknowledges the support of the Erasmus Mundus External Cooperation Window (EM ECW) of the European Commission, grant agreement number 2009-1663/001-001-ECW and the European Regional Development Fund (ERDF/EFRO), project P1205 EMOVO. The experiments presented in this study were conducted at the combustion laboratory of a stove manufacturing plant, Belgium. The author would like to express sincere thanks to the entire department $\mathrm{MECH}$, VUB and the combustion laboratory of a stove manufacturing plant, Belgium for their help in conducting the experiments and support.

\section{References}

Bäfver, L. S., Leckner, B., Tullin, C. \& Berntsen, M. (2011). Particle emissions from pellets stoves and modern and oldtype wood stoves, Biomass and Bioenergy 35, 3648-3655.

Belgium, R.-D. (2010) Royal Decree regulating minimum performance requirements and pollutant emission levels for solid fuel-fired heating appliances.

Bell, S. March (2001). A beginner's guide to uncertainty of measurements, United Kingdom, National Physical Laboratory.

Chafe, Z., Brauer, M., Heroux, M.-E., Klimont, Z., Lanki, T., Salonen, R. O. \& Smith, K. R. (2015). Residential heating with wood and coal: health impacts and policy options in Europe and North America, World Health Organization

Chin, G. T., Chen, J.-Y., Rapp, V. H. \& Dibble, R. (2011). 'Development and Validation of a Reduced DME Mechanism Applicable to Various Combustion Modes in Internal Combustion Engines, Journal of Combustion, 1-8.

Cofala, J. \& Klimont, Z.(2012).Emissions from households and other small combustion sources and their reduction potential. Austria, International Institute of Applied Systems Analysis (IIASA).

EN-13229(2002). Open fires and inserts solid fuel - Requirements and test methods, French Association Standardization.

EN-14785(2006). Residential space heating appliances fired by wood pellets: Requirements and test methods', Belgian Standards Institute (NBI).

Englert, N. (2004). Fine particles and human health - a review of epidemiological studies. Toxicology Letters 149, 235-242. 
Favez, O., Cachier, H., Sciare, J., Sarda-Esteve, R. \& Martinon, L. (2009). Evidence for a significant contribution of wood burning aerosols to PM2.5 during the winter season in Paris, France, Atmospheric Environment 43, 3640-3644.

Fiedler, F. \& Persson, T. (2009). Carbon monoxide emissions of combined pellet and solar heating systems. Applied Energy $86,135-143$.

Gesellschaft, D. C. (2011). DINPlus certification scheme-Room heaters for solid fuels, Germany.

Gonzalez JF, Gonzalez-Garca CM, Ramiro A, G. J., Sabio E \& A, M. (2004). Combustion optimisation of biomass residue pellets for domestic heating with a mural boiler. Biomass and Bioenergy 27, 145-154.

Heschel, W., Rweyemamu, L., Scheibner, T. \& Meyer, B. (1999). Abatement of emissions in small-scale combustors through utilisation of blended pellet fuels. Fuel Processing Technology $61,223-242$.

Hukkanen, A., Kaivosoja, T., Sippula, O., Nuutinen, K., Jokiniemi, J. \& Tissari, J. (2012). Reduction of gaseous and particulate emissions from small-scale wood combustion with a catalytic combustor. Atmospheric Environment, 50, 12-23

Johansson, L. S., Leckner, B., Gustavsson, L., Cooper, D., Tullin, C. \& Potter, A. (2004). Emission characteristics of modern and old-type residential boilers fired with wood logs and wood pellets, Atmospheric Environment 38, 4183-4195.

Khan, A., De Jong, W., Jansens, P. \& Spliethoff, H. (2009) 'Biomass combustion in fluidized bed boilers: Potential problems and remedies, Fuel Processing Technology 90, 2150.

Mediavilla, I., FernÃßndez, M. \& Esteban, L. (2009). Optimization of pelletisation and combustion in a boiler of $17.5 \mathrm{~kW}$ th for vine shoots and industrial cork residue, Fuel Processing Technology 90, 621-628.

Mudgal, S.: (2009) Solid fuel small combustion installations-Lot 15', European Commission-DG TREN, pp. 1-110.

Obaidullah, M. (2014) Particle Emissions from Small Scale Biomass Combustion Appliances, Department of Mechanical Engineering Vrije Universiteit Brussel

Obaidullah, M., Bram, S., Thomassin, J. D., Duquesne, T., Dyakov, I. V., Contino, F. \& De Ruyck, J. (2014). CO Emission Measurements and Performance Analysis of $10 \mathrm{~kW}$ and 20 kW Wood Stoves. Energy Procedia 61, 2301-2306.

Obaidullah, M., Bram, S., Verma, V. \& De Ruyck, J. (2012). A Review on Particle Emissions from Small Scale Biomass Combustion. International Journal of Renewable Energy Research (IJRER) 2, 147-159.

Obernberger, I. \& Mandl, C. (2011). Survey on the present state of particle precipitation devices for residential biomass combustion with a nominal capacity up to $50 \mathrm{~kW}$ in IEA Bioenergy Task32 member countries, Graz, Austria, Graz University of Technology.

Ohman, M., Boman, C., Hedman, H., Nordin, A. \& Bostrom, D. (2004). Slagging tendencies of wood pellet ash during combustion in residential pellet burners', Biomass and Bioenergy 27, 585-596.

Qiu, G. (2013). Testing of flue gas emissions of a biomass pellet boiler and abatement of particle emissions, Renewable Energy 50, 94-102.

Roy, M. M. \& Corscadden, K. W. (2012). An experimental study of combustion and emissions of biomass briquettes in a domestic wood stove, Applied Energy 99, 206-212.

Schmidl, C., Luisser, M., Padouvas, E., Lasselsberger, L., Rzaca, M., Ramirez-Santa Cruz, C., Handler, M., Peng, G., Bauer, H. \& Puxbaum, H. (2011). Particulate and gaseous emissions from manually and automatically fired small scale combustion systems, Atmospheric Environment, 45, 74437454.

Sippula, O., Hokkinen, J., Puustinen, H., Yli-Pirila, P. \& Jokiniemi, J. (2009). Comparison of particle emissions from small heavy fuel oil and wood-fired boilers, Atmospheric Environment 43, 4855-4864.

Sippula, O., Hytonen, K., Tissari, J., Raunemaa, T. \& Jokiniemi, J. (2007), Effect of wood fuel on the emissions from a top-feed pellet stove, Energy \& Fuels 21, 1151-1160.
Taylor, J. R. (1997). An introduction to error analysis: the study of uncertainties in physical measurements, University science books.

Tissari, J. (2008). Fine particle emissions from residential wood combustion', Ph. D., Department of Environmental Science, Finland.

Tissari, J., Hytonen, K., Sippula, O. \& Jokiniemi, J. (2009). The effects of operating conditions on emissions from masonry heaters and sauna stoves, Biomass and Bioenergy 33, 513520.

Toscano, G., Duca, D., Amato, A. \& Pizzi, A. (2014) Emission from realistic utilization of wood pellet stove, Energy 68, 644-650.

Verma, V., Bram, S., Gauthier, G. \& De Ruyck, J. (2011) 'Evaluation of the performance of a multi-fuel domestic boiler with respect to the existing European standard and quality labels: Part-1, Biomass and Bioenergy 35, 80-89.

Vicente, E., Duarte, M., Tarelho, L., Nunes, T., Amato, F., Querol, X., Colombi, C., Gianelle, V. \& Alves, C. (2015). Particulate and gaseous emissions from the combustion of different biofuels in a pellet stove, Atmospheric Environment 120, 1527.

Vicente, E. D. \& Alves, C. A. (2018). An overview of particulate emissions from residential biomass combustion, Atmospheric Research 199, 159-185.

Villeneuve, J., Palacios, J. H., Savoie, P. \& Godbout, S. (2012). A critical review of emission standards and regulations regarding biomass combustion in small scale units $(<M W)$, Bioresource Technology 111, 1-11. 